\title{
Creating an Ultrasound Scholarly Concentration Program for Medical Students
}

\author{
Daniel R Bacon (iD) \\ Keri Cowles' \\ Diwash Thapa' \\ Alexander White (ID) \\ Austin J Allen (iD) \\ John Doughton ${ }^{2}$ \\ Gary Beck Dallaghan ${ }^{3}$ \\ Sheryl G Jordan ${ }^{4}$ \\ 'University of North Carolina School of \\ Medicine, Chapel Hill, NC, USA; \\ ${ }^{2}$ Department of Family Medicine, \\ University of North Carolina School of \\ Medicine, Chapel Hill, NC, USA; ${ }^{3}$ Office \\ of Medical Education, University of North \\ Carolina School of Medicine, Chapel Hill, \\ NC, USA; ${ }^{4}$ Department of Radiology, \\ University of North Carolina School of \\ Medicine, Chapel Hill, NC, USA
}

Correspondence: Sheryl G Jordan University of North Carolina School of Medicine, 32I South Columbia Street, Chapel Hill, NC, 275I4, USA

Email sheryl_jordan@med.unc.edu

\begin{abstract}
Introduction: Point of care ultrasound (POCUS) is increasingly prevalent and standardized in undergraduate medical education (UME); however, roughly $25 \%$ of United States medical schools lack an ultrasound curriculum. One of the commonly cited barriers to ultrasound training in UME is faculty time resources. Here, we describe an ultrasound scholarly concentration program (SCP) designed to provide medical students with ultrasound opportunities in clinical and scholarly domains, while reducing the need for extensive faculty resources.
\end{abstract}

Methods: SCPs at the University of North Carolina School of Medicine have 3 requirements: an elective course, a longitudinal portfolio, and a final scholarly project. Thus, the ultrasound SCP was designed to comprise an introductory clinical elective to ultrasound, development of a longitudinal scan portfolio, and a final scholarly project in ultrasound related research or educational innovation. A review of the literature and search of the top 50 US medical schools by US News \& World Report was performed to assess the novelty of the ultrasound SCP.

Results: To the best of our knowledge, the ultrasound SCP is the first scholarly concentration, track or pathway offered to medical students in the United States. It is the first description of a student designed and student led curriculum focused on providing meaningful ultrasound opportunities to students without necessitating unavailable faculty resources and educational infrastructure.

Conclusion: A novel ultrasound SCP is described which has clinical aims to expose students to clinical ultrasound as well as scholarly aims to facilitate ultrasound related research and educational innovation. It is designed to enable students to make ultrasound a defining characteristic of their medical school experience. The SCP relies on motivated student involvement and near-peer teaching in a way that is self-sustaining and selfimproving.

Keywords: ultrasound, ultrasound curriculum, undergraduate medical education, scholarly concentration

\section{Introduction}

Point of care ultrasound (POCUS) training in undergraduate medical education (UME) is becoming increasingly more prevalent and standardized, yet the most recent analysis found that greater than $25 \%$ of US medical schools lack an ultrasound curriculum. ${ }^{1}$ The need for ultrasound education in UME is increasingly recognized by published consensus statements, ${ }^{2,3}$ and recently the Canadian Ultrasound Consensus for Undergraduate Medical Education outlined 85 ultrasound curricular elements recommended for inclusion in UME. ${ }^{4}$ Despite need, integrating longitudinal ultrasound curriculum as accomplished at institutions like the University of South Carolina ${ }^{5-7}$ is costly and challenging. In particular, protected faculty time is cited as a major barrier. ${ }^{1}$ 
In 2017, undergraduate ultrasound education at the University of North Carolina School of Medicine (UNC) was limited to a single introductory elective in which student interest greatly overwhelmed its 40 -student capacity. Moreover, opportunities for students to further develop skills and pursue scholarly endeavors related to ultrasound were unstructured with limited visibility.

We describe a student-led initiative to design and implement an ultrasound scholarly concentration program (SCP) which has both clinical and scholarly aims. Its clinical aims are to expose students to ultrasound and its scholarly aims are to facilitate student involvement in ultrasound related research and educational innovation. The SCP allows students to make ultrasound a defining characteristic of their medical school experience in way that is self-sustaining, relying on motivated student leadership with minimal faculty resources.

\section{Methods}

\section{Scholarly Concentration Programs}

This description of the SCP was considered exempt by the University of North Carolina Institutional Review Board considering its descriptive nature. SCPs at the UNC School of Medicine are extra-curricular enrichment pathways for students to learn more extensively about a discipline than would otherwise be encountered through universal graduation requirements. Additionally, they facilitate mentorship and scholarly contributions within a given field. ${ }^{8}$ As of July 2021, there were 8 SCP options at UNC SOM: global health, medical education, clinician leadership in quality and safety, care of the older patient, humanities and social sciences, medical education supporting sexuality and gender expressions, nutrition and most recently, ultrasound. ${ }^{9}$ Currently, there are 12 students enrolled in the ultrasound SCP from the class of 2023 and 10 students from the class of
2024. A total of 13 students applied from the class of 2023 , and a total of 25 students applied from the class of 2024. Table 1 depicts the ultrasound SCP requirements in chronological fashion over the course of medical school. Students final scholarly project involving topic-related research or educational innovation; for the Ultrasound SCP, each are discussed in detail below.

\section{Elective Course: Radiology 121, Ultrasound Fundamentals}

Originally designed as a summer in-person didactic session experience followed by hands on practice, this curriculum was adapted to meet physical distancing requirements imposed by the COVID-19 pandemic. A completely virtual and asynchronous pre-clinical curriculum was designed for rising 2nd year medical students to complete during the summer after their first year of medical school. Table 2 lists the topics and course requirements which include online didactics (EMSono, LLC, Canton, OH), quiz assessments and scan assignments utilizing handheld butterfly ultrasound probes (Butterfly Network, Inc. Guilford, CT) which students were provided continuous access to for the duration of the course. The course aim is to introduce students to normal sonoanatomy, and to provide hands on experience with ultrasound technique prior to clinical rotations. Studentselected scans are evaluated according to a standardized grading scheme which assessed orientation, gain, depth, centering, complete visualization of correct anatomy and quality of measurements.

This 3-credit hour pre-clinical course is now officially registered in the UNC School of Medicine course catalogue. Our preliminary results showed increased student confidence levels and demonstrated that remote, asynchronous ultrasound education is feasible, and greatly reduces faculty time requirements. Final evaluation results are

Table I Academic Calendar for the Ultrasound Scholarly Concentration Program

\begin{tabular}{|c|c|c|c|c|c|c|c|c|c|c|c|c|}
\hline & Jan & Feb & Mar & Apr & May & Jun & Jul & Aug & Sep & Oct & Nov & Dec \\
\hline MSI & & & & & & & Begin medical school & & & Application to US SCP & & \\
\hline MSI/MS2 & & & & & & \multicolumn{3}{|c|}{$\begin{array}{l}\text { Fundamentals of ultrasound elective } \\
\text { (Radiology I2I) }\end{array}$} & & & & \\
\hline MS3 & \multicolumn{12}{|c|}{$\begin{array}{l}\text { Monthly ultrasound case conference, scholarly project round table conference, Radiology } 121 \text { teaching opportunities, development of } \\
\text { scan portfolio and scholarly project }\end{array}$} \\
\hline MS4 & \multicolumn{12}{|c|}{$\begin{array}{l}\text { Continue scan portfolio and final project, present work at academic conferences and/or publish findings in academic journals, } \\
\text { participate as in near-peer teaching and mentorship. }\end{array}$} \\
\hline
\end{tabular}

Abbreviations: MSX, medical student year X (I,2,3,4); US, ultrasound; SCP, scholarly concentration program. 
Table 2 Summary of Topics, Quiz and Scan Requirements for Fundamentals of Ultrasound Elective (RADY I2I)

\begin{tabular}{|c|c|c|c|}
\hline Topic & Subtopics/Modules (Minutes) & Number of Quizzes & Scans (1-2 of Each) \\
\hline $\begin{array}{l}\text { Practical } \\
\text { Scanning }\end{array}$ & $\begin{array}{l}\text { Total time: } 55 \text { min } \\
\text { I.Sound wave essentials (4) } \\
\text { 2.Ultrasound transmission in human tissue (10) } \\
\text { 3.Instrumentation (6) } \\
\text { 4.Knobology (15) } \\
\text { 5.Greyscale optimization (6) } \\
\text { 6.Artifacts (II) } \\
\text { 7.Scanning principles (3) }\end{array}$ & 4 & None \\
\hline $\begin{array}{l}\text { FAST } \\
\text { Abdomen } \\
\text { and } \\
\text { Pericardium }\end{array}$ & $\begin{array}{l}\text { Total time: II6 min } \\
\text { I.Hemoperitoneum (8) } \\
\text { 2.Perihepatic window (3I) } \\
\text { 3.Perisplenic window (34) } \\
\text { 4.Pelvic window (14) } \\
\text { 5.Hemopericardium (5) } \\
\text { 6.Subcostal window (9) } \\
\text { 7.PSLA window (13) } \\
\text { 8.Interpreting PSLA window (10) } \\
\text { 9.Optional: Clinical Applications }\end{array}$ & 5 & $\begin{array}{l}\text { I-2 FAST exams (Subxiphoid, RUQ, LUQ, suprapubic } \\
\text { windows) }\end{array}$ \\
\hline $\begin{array}{l}\text { Gallbladder } \\
\text { and Renal }\end{array}$ & $\begin{array}{l}\text { Total time: } 78 \text { min } \\
\text { I.Gallbladder introduction (5) } \\
\text { 2.Sagittal exam (9) } \\
\text { 3.Transverse exam (7) } \\
\text { 4.Gallbladder shape (4) } \\
\text { 5.Gallbladder size (4) } \\
\text { 6.Gallbladder lumen (13) } \\
\text { 7.Gallbladder wall/pericholecystic fluid (8) } \\
\text { 8.Common bile duct (4) } \\
\text { 9.Introduction to renal (4) } \\
\text { 10.Right renal (6) } \\
\text { II.Left renal (6) } \\
\text { 12.Urinary bladder (8) } \\
\text { 13.Optional: Assessing for hydronephrosis, clinical } \\
\text { applications }\end{array}$ & 3 & $\begin{array}{l}\text { I-2 scans of each of the following: } \\
\text { - Gallbladder with measurements of wall thickness, sagittal } \\
\text { diameter, transverse diameter, and common bile duct } \\
\text { - Renal (longitudinal/transverse) and bladder }\end{array}$ \\
\hline $\begin{array}{l}\text { Cardiac and } \\
\text { Pulmonary }\end{array}$ & $\begin{array}{l}\text { Total time: } 55 \text { min } \\
\text { I.Transthoracic windows (10) } \\
\text { 2.Visual estimation of LV function (13) } \\
\text { 3.IVC (9) } \\
\text { 4.Search for pneumothorax (4) } \\
\text { 5.Focused thoracic exam (19) } \\
\text { 6.Optional: effusion and tamponade physiology, } \\
\text { acute right heart strain, the crashing patient, }\end{array}$ & 3 & $\begin{array}{l}\text { I-2 scans of each of the following: } \\
\text { - PSLA, PSSA, apical } 4 \text { chamber } \\
\text { - IVC with respiration } \\
\text { - Lung sliding }\end{array}$ \\
\hline Vascular & $\begin{array}{l}\text { Total time: } 108 \text { min } \\
\text { I.Vascular access essentials ( } 3 \text { I) } \\
\text { 2.Long axis approach (4) } \\
\text { 3.Short axis approach (II) } \\
\text { 4.oblique axis approach (3) } \\
\text { 5.Introduction to Aorta (3) } \\
\text { 6.Sagittal aorta (15) } \\
\text { 7.Transverse aorta (I2) } \\
\text { 8.Interpreting the aorta exam (22) } \\
\text { 9.Abdominal aortic exam (7) } \\
\text { 10.Optional: central line placement, peripheral line } \\
\text { placement, aorta clinical applications }\end{array}$ & 4 & $\begin{array}{l}\text { I-2 scans of each of the following: } \\
\text { - Aorta (longitudinal and transverse with measurements at } \\
\text { the levels of the celiac access, SMA, and proximate to } \\
\text { the iliac bifurcation }\end{array}$ \\
\hline
\end{tabular}

Abbreviations: FAST, focused assessment with sonography for trauma; PSLA, parasternal long axis; PSSA, parasternal short axis; LV, left ventricle; RUQ, right upper quadrant; LUQ, left upper quadrant; IVC, inferior vena cava; SMA, superior mesenteric artery. 
being reported elsewhere by Bacon et al, and these results are in accord with another recently reported example of virtual ultrasound education for medical students. ${ }^{10}$

\section{Longitudinal Portfolio, Case Conferences and Website}

Student scans are archived in the Butterfly cloud database (Butterfly Network, Inc. Guilford, CT), which allows for efficient faculty evaluation and feedback in the form of a comment attached to the student's scan. Additionally, optional office hours and in-person scan opportunities are offered to students desiring to discuss questions related to particular scans or questions related to technique. At present, there is no set number of scans that are required for the portfolio; rather by design, this is an opportunity for students to pursue self-directed learning with the opportunity to track progress over time and incorporate faculty feedback. Students seeking advanced ultrasound proficiency may benefit from individualized learning plans over the course of medical school; aspirational examples include previously described and standardized ultrasound milestones. ${ }^{11}$

Students also participate in a monthly case conference and are required to attend five per year and present at one session during their 3rd or 4th year of medical school. Case presentations are 30 minutes and center around a clinical vignette in which the student used POCUS during their rotations. Students present the history, indication for ultrasound, an example of the scan they performed, diagnosis and management of the condition, and present a pertinent review of the literature related to a specific clinical question. For example, utilizing skills from Radiology 121, a student recently performed echocardiography to identify a pericardial effusion (Figure 1). The student logged this scan into a portfolio and prepared a case presentation for monthly conference centered around the clinical question: Can POCUS decrease the time to diagnosis for acute pericarditis? The full presentation can be viewed on our website. ${ }^{12,13}$

Students are encouraged to submit these presentations to be considered for peer-reviewed publication on the ultrasound SCP website, which was originally created as an open-access educational radiology website for medical students. ${ }^{14}$ This website has been used successfully in a variety of other educational capacities including studentled virtual journal club presentations ${ }^{15,16}$ and studentauthored teaching files. ${ }^{17-19}$ At present, the ultrasound
SCP peer review team is comprised of 3 resident physicians who are blinded to the case conference presentation. One reviewer is assigned at random to the case and asked to make recommendations for acceptance or revisions for resubmission. Final publication decisions are made by the SCP faculty advisor (SGJ).

\section{Scholarly Projects}

Over the course of the SCP, students are required to participate in a scholarly project which could involve participation in an ultrasound related research project or educational innovation. Research requirements are flexible, but could include basic science, clinical research, or quality improvement aims. Alternatively, students could propose an educational innovation such as developing modules, simulators, enhancements of the evaluation process, or reflective teaching experiences. Examples of current project proposals are described in Table 3.

Students are encouraged to present project proposals to peer student leaders (DRB, KC) in the form of a PowerPoint presentation with the elements discussed above. This format reinforces well-reported advantages of near-peer teaching and mentoring. ${ }^{20-23}$ Student leaders help refine research design ideas and assist with practical guidance such as with applications for Institutional Review Board approval. Students then make project proposals to faculty advisors (SGJ), and ideally present at one of the monthly conferences discussed above for further feedback. In addition to formal presentations, students have informal opportunities during "round table" discussions which occur every 3-4 months in place of the case conference discussed above. Students are encouraged to present ideas at all stages of development, whether at initial hypothesis or presentation of completed research. One or two students make formal research proposals at these meetings which include background literature review, study design, methods, and anticipated barriers. Students and faculty participate by offering feedback and suggestions. Anecdotally, we have found that these meetings are effective at refining student research plans and are idea-generating for students at all levels in the SCP. This format has also helped to facilitate connections between students and faculty mentors; for example, one student interested in 3D printing and biomedical engineering of high-fidelity ultrasound simulators was connected with faculty members in these respective departments. Students are encouraged to present their project findings 


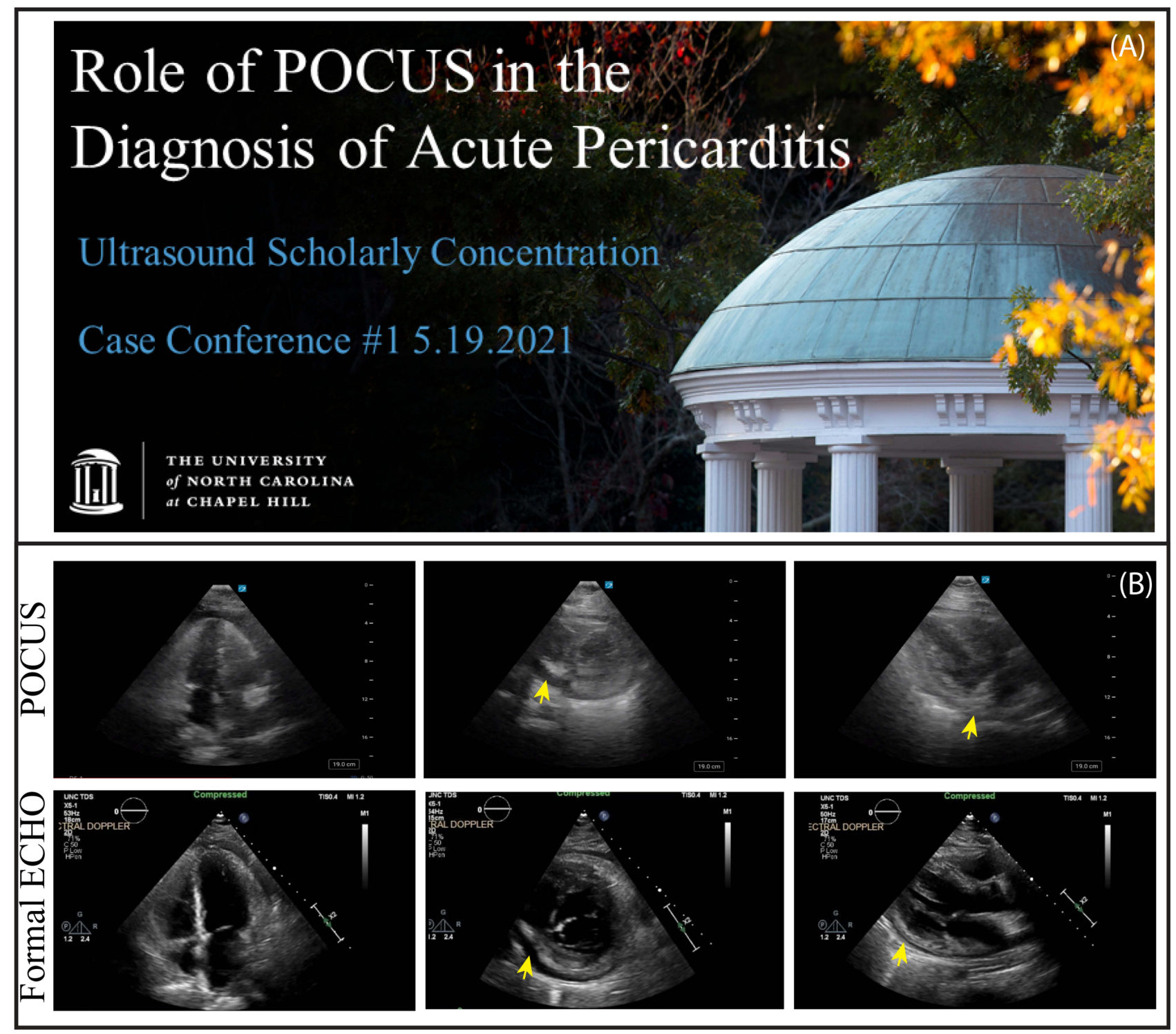

Figure I Student presentation example for monthly case conference. top panel: Title slide. Bottom panel: Comparing POCUS identified pericardial effusion to formal echocardiography.

at regional, national, and international academic conferences and to publish their work in academic journals.

In this way, the ultrasound SCP has developed a culture of scholarly inquiry and collaboration which is selfsustaining in that student research ideas often further advance SCP goals (ie, a student project to improve our Radiology 121 elective). This underlines the advantage of motivated student leadership, as it is often cited that faculty resources are a rate-limiting step in ultrasound education. ${ }^{1,24}$

\section{Results}

\section{Novelty}

The concept of scholarly concentrations, tracks or pathways is well reported in the literature, and has gained popularity in UME. In particular, SCPs at UNC were modeled after the SCPs at the Warren Alpert medical school of Brown University originally reported in $2007 .^{25}$ A simple screening of the top 50 US medical schools (separately by research and primary care) by US News and World report ${ }^{26}$ revealed that at least $68 \%(n=34)$ of schools reported provision of longitudinal scholarly concentrations, tracks or pathways. These SCPs center around topics that are not traditionally covered in medical school beyond a superficial depth, including: global health, care of the older patient, nutrition, genetics in medicine, humanities and social sciences, to name a few. However, SCPs rarely, if ever, focus on a specific clinical skill. Thus, ultrasound appears to be a unique and novel scholarly 
Table 3 Examples of Current Student Scholarly Project Proposals Organized by Theme

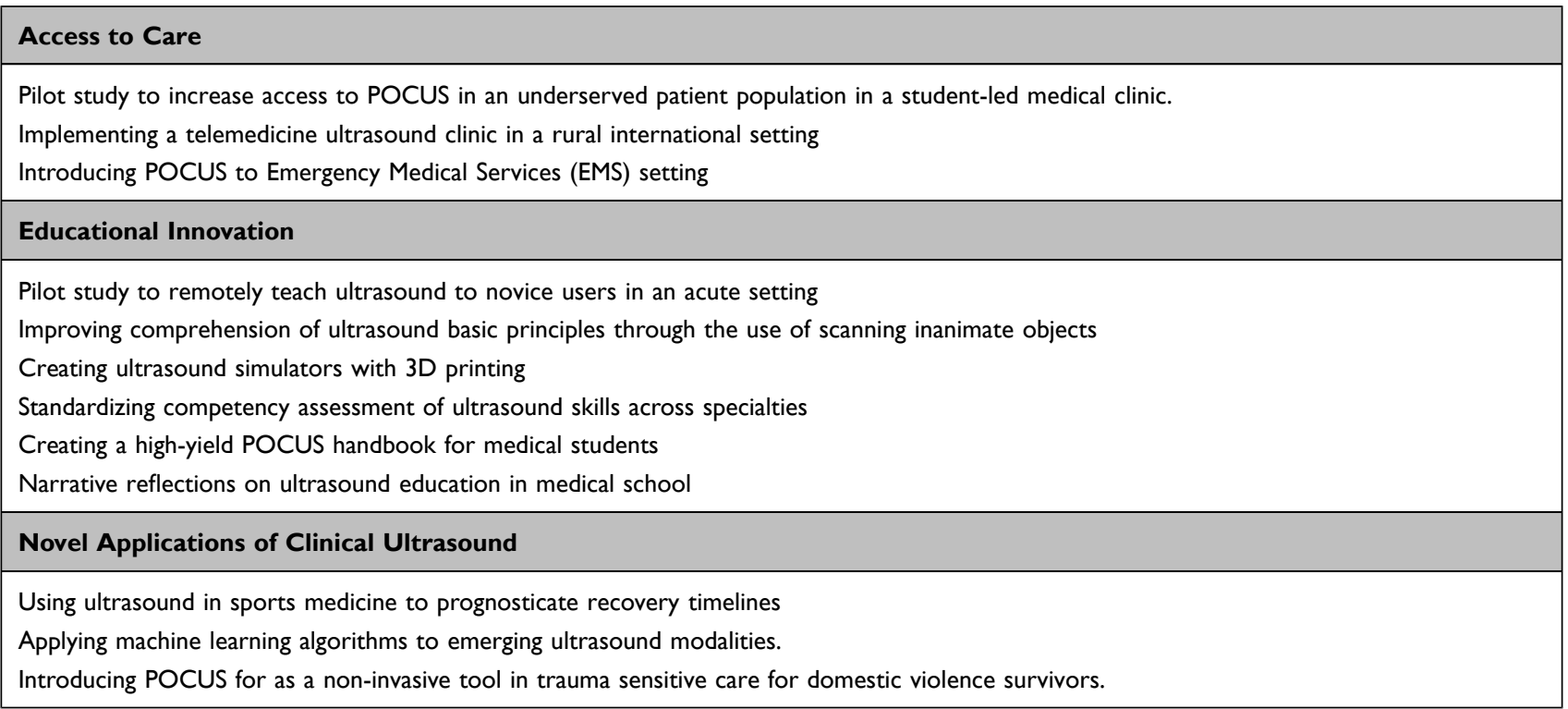

concentration that fits the general paradigm of a topic that is of interest to students but is covered only at a superficial level at many institutions. To the best of our knowledge, there are no reports of ultrasound SCPs in the literature. Furthermore, prior to instituting our SCP, we screened school of medicine websites for the same top 50 US medical schools with the search terms, "ultrasound", "concentration", "pathway", and "track", which did not reveal any other scholarly concentration in ultrasound. Thus, the ultrasound SCP at UNC is a novel contribution to medical education literature and is likely the first of its kind.

\section{Discussion}

\section{Reproducibility and Limitations}

The success of the ultrasound SCP has relied upon motivated student involvement, simplicity and flexibility, supportive faculty mentors, and modest funding. As described above, faculty resource limitations are a commonly cited barrier to ultrasound education. Based on our experience, a prospective ultrasound SCP is likely to succeed if it is initiated and sustained by students. For this reason, starting with an interest group may be a reasonable place to identify driven student leaders who are prepared to advocate for the curriculum, fulfill a variety of administrative tasks, and be highly involved in near-peer teaching and mentorship.

The simplicity of the SCP is important. We focus our improvement efforts on only 3 discrete components: a pre-clinical elective, a longitudinal component (case conference and scan portfolio), and a final scholarly project. Simplicity begets flexibility which is appreciated by medical students interested in gaining new skills efficiently without distracting from their primary medical education. Starting with the pre-clinical elective, a virtual and remote curriculum during the summer after the first year of medical school allows students to complete assignments at their convenience so that they can simultaneously engage in other opportunities. To promote flexibility during the longitudinal component, we intentionally limit obligatory meetings and rigid scan requirements, especially during clinical rotations. Scholarly projects are intrinsically flexible as they are open-ended opportunities that students can begin working on at any point during medical school.

Lastly, we are fortunate to have had funding for 10 handheld ultrasound probes $(\$ 2000 /$ probe $)$ which we use for Radiology 121 and loan out to students for scholarly projects and clinical rotations. Additionally, we have funding to purchase commercial didactic resources $(\sim \$ 100 /$ student for annual subscription). Although these resources certainly enhance our curriculum, we were prepared to implement the SCP with or without this funding utilizing standard ultrasound machines which are available ubiquitously at academic hospitals and schools of medicine.

Possible barriers to prospective SCPs include availability and usability of secure databases for archiving scans, the availability of motivated student leaders and a committed faculty mentor, as well the availability of 
educational content. However, we note comprehensive open-source educational modules which are available through the University of South Carolina School of Medicine, and we suggest this as a starting point. ${ }^{27}$

\section{Conclusion}

A novel student-led ultrasound SCP was designed and implemented at the UNC School of Medicine. This curriculum can serve as a model to other institutions who look to increase clinical and scholarly ultrasound opportunities for students. The strengths of this curriculum include its simplicity, flexibility, and reliance on motivated students in manner that facilitates leadership opportunities in and is self-sustaining and self-improving.

\section{Disclosure}

The authors report no conflicts of interest.

\section{References}

1. Nicholas E, Ly AA, Prince AM, Klawitter PF, Gaskin K, Prince LA. The current status of ultrasound education in United States medical schools. J Ultrasound Med. 2021. doi:10.1002/jum.15633

2. Hoffmann B, Blaivas M, Abramowicz J, et al. Medical Student Ultrasound Education, a WFUMB Position Paper, Part II. A consensus statement of ultrasound societies. Med Ultrason. 2020;22(2):220-229. doi:10.11152/mu-2599

3. Dinh VA, Lakoff D, Hess J, et al. Medical Student Core Clinical Ultrasound Milestones: a Consensus Among Directors in the United States. J Ultrasound Med. 2016;35(2):421-434. doi:10.7863/ ultra. 15.07080

4. Ma IWY, Steinmetz P, Weerdenburg K, et al. The Canadian Medical Student Ultrasound Curriculum: a Statement From the Canadian Ultrasound Consensus for Undergraduate Medical Education Group. J Ultrasound Med. 2020;39(7):1279-1287. doi:10.1002/jum.15218

5. University of South Carolina School of Medicine website. Integrated Ultrasound. Available from: https://sc.edu/study/colleges_schools/med icine/education/md_program/curriculum/integrated_ultrasound/index. php. Accessed July 9, 2021.

6. Hoppmann R, Cook T, Hunt P, et al. Ultrasound in medical education: a vertical curriculum at the University of South Carolina School of Medicine. J S C Med Assoc. 2006;102(10):330-334.

7. Hoppmann R, Rao VV, Bell F, et al. The evolution of an integrated ultrasound curriculum (iUSC) for medical students: a 9-year experience. Crit Ultrasound J. 2015;7(1):18. doi:10.1186/s130895-0035-3

8. University of North Carolina School of Medicine website. Scholarly Concentration Programs. Available from: https://www.med.unc.edu/ $\mathrm{md} /$ curriculum/primary-care-programs-and-scholarly-tracks/scholarlyconcentration-program/. Accessed July 9, 2021.

9. Bacon DR. Ultrasound Scholarly Concentration Program. University of North Carolina School of Medicine website. Available from: https:// www.med.unc.edu/md/curriculum/primary-care-programs-andscholarly-tracks/scholarly-concentration-program/ultrasound/. Accessed September 22, 2021.
10. Höhne H, Recker F, Schmok E, et al. Conception and Feasibility of a Digital Tele-Guided Abdomen, Thorax, and Thyroid Gland Ultrasound Course for Medical Students (TELUS study). Ultraschall Med. 2021. doi:10.1055/a-1528-1418

11. Lewiss RE, Pearl M, Nomura JT, et al. CORD-AEUS: consensus document for the emergency ultrasound milestone project. Cad Emerg Med. 2013;20(7):740-745. doi:10.1111/acem.12164

12. Thapa D. Role of POCUS in the diagnosis of acute pericarditis; 2021. https://msrads.web.unc.edu/. Accessed July 9, 2021.

13. Bacon DR, Thapa D, Jordan SG Ultrasound Scholarly Concentration Program. UNC Radiology Medical Student website. Available from: https://msrads.web.unc.edu/us-scp/. Accessed July 9, 2021.

14. Mauro DM, Ellis JA, Lilly JF, Beck Dallaghan GL, Jordan SG. Creating an open-access educational radiology website for medical students: what radiology educators need to know. Acad Radiol. 2020. doi:10.1016/j.acra.2020.08.021

15. Journal Club. UNC Radiology Medical Student Website. Available from: https://msrads.web.unc.edu/journal-club/. Accessed July 9, 2021.

16. Slanetz PJ, Bedi H, Kesler T, Chetlen A. Optimizing journal clubs in the post-COVID-19 Era. J Am Coll Radiol. 2020;17(11):1496-1498. doi:10.1016/j.jacr.2020.07.031

17. Teaching File. UNC Radiology Medical Student website. Available from: https://msrads.web.unc.edu/teaching-file/. Accessed July 9, 2021.

18. Lilly JF, Verma NV, Jordan SG, et al. Medical student imaging case files in the cloud. Clin Teach. 2020;17(3):275-279. doi:10.1111/ tct. 13059

19. Bozung BR, Houston K, Lilly JF, et al. Student-Led Peer Review of an Online Teaching File: perspectives after 2 Years. Med Educ Online. 2021;26(1):1843356. doi:10.1080/10872981.2020.1843356

20. Rees EL, Quinn PJ, Davies B, Fotheringham V. How does peer teaching compare to faculty teaching? A systematic review and meta-analysis. Med Teach. 2016;38(8):829-837. doi:10.3109/ 0142159X.2015.1112888

21. Hill AG, Srinivasa S, Hawken SJ, et al. Impact of a resident-asteacher workshop on teaching behavior of interns and learning outcomes of medical students. J Grad Med Educ. 2012;4(1):34-41. doi:10.4300/JGME-D-11-00062.1

22. Cumberworth J, Apperley H, Francis I. Organising near-peer teaching programmes for clinical professionals. Clin Teach. 2020;17 (2):122-125. doi:10.1111/tct.12983

23. Hall S, Harrison $\mathrm{CH}$, Stephens J, et al. The benefits of being a near-peer teacher. Clin Teach. 2018;15(5):403-407. doi:10.1111/ tct. 12784

24. Dinh VA, Fu JY, Lu S, et al. Integration of ultrasound in medical education at United States medical schools: a National Survey of Directors' Experiences. J Ultrasound Med. 2016;35(2):413-419. doi:10.7863/ultra. 15.05073

25. Rickards E, Borkan J, Gruppuso PA, et al. Educating the next generation of leaders in medicine: the Scholarly Concentrations Program at the Warren Alpert Medical School of Brown University. Med Health RI. 2007;90(9):275-6, 280-2.

26. 2022 Best Medical Schools. U.S. News \& World Report website. Available from: https://www.usnews.com/best-graduate-schools/topmedical-schools. Accessed July 9, 2021.

27. Ultrasound Institute Resources. University of South Carolina School of Medicine website. Available from: https://sc.edu/study/colleges schools/medicine/centers_and_institutes_new/ultrasound_institute/ resources.php. Accessed July 9, 2021. 


\section{Publish your work in this journal}

Advances in Medical Education and Practice is an international, peerreviewed, open access journal that aims to present and publish research on Medical Education covering medical, dental, nursing and allied health care professional education. The journal covers undergraduate education, postgraduate training and continuing medical education including emerging trends and innovative models linking education, research, and health care services. The manuscript management system is completely online and includes a very quick and fair peer-review system. Visit http://www.dovepress.com/testimonials.php to read real quotes from published authors.

Submit your manuscript here: http://www.dovepress.com/advances-in-medical-education-and-practice-journal 